\title{
Raphidascaris (Ichthyascaris) arii sp. n. (Nematoda: Anisakidae), a new ascaridoid nematode from marine catfishes in the Gulf of Thailand
}

\author{
T. YOOYEN ${ }^{1}$, F. MORAVEC ${ }^{2 *}$, C. WONGSAWAD ${ }^{1}$
}

\begin{abstract}
${ }^{1}$ Department of Biology, Faculty of Science, Chiang Mai University, Thailand; ${ }^{2 *}$ Institute of Parasitology, Biology Centre, Academy of Sciences of the Czech Republic, Branišovská 31, 37005 České Budějovice,

Czech Republic, E-mail: moravec@paru.cas.cz
\end{abstract}

\begin{abstract}
Summary
A new nematode species, Raphidascaris (Ichthyascaris) arii sp. n. (Anisakidae), is described from male and female specimens found in the intestine of two species of marine siluriform fishes, the spotted catfish Arius maculatus (Thunberg) (Ariidae) (type host) and the striped eel catfish Plotosus lineatus (Thunberg) (Plotosidae) from the coastal region of the Gulf of Thailand, Thailand. Based on light and scanning electron microscopy examinations, the new species differs from other nine representatives of the subgenus Ichthyascaris Wu, 1949 mainly in the length of spicules $(210-333 \mu \mathrm{m})$, body length of gravid females $(10-17 \mathrm{~mm})$, and in the presence of small cuticular spines or protuberances on the tail tip of both sexes and $21-30$ pairs of preanal and 8 pairs of postanal papillae in the male. This is the first species of this subgenus reported from fishes of the order Siluriformes and the first species of the subgenus Ichthyascaris $\mathrm{Wu}, 1949$ recorded from the Gulf of Thailand.
\end{abstract}

Keywords: parasitic nematode; Raphidascaris; Ichthyascaris; marine fish; Arius; Plotosus; Gulf of Thailand

\section{Introduction}

The fauna of nematode parasites of marine and brackishwater fishes in Thailand remains little known. Bhaibulaya (1981) reported on ascaridoid larvae in fishes of the Gulf of Thailand and Sirikanchana (1982), in his checklist of parasites of fishes in Thailand listed, without localities, not specifically identified adult nematodes of three genera and larvae of four genera from Thai marine fishes. Moravec et al. (2006, 2007) reported Procamallanus anguillae Moravec et al., 2006 and Heliconema longissimum (Ortlepp, 1923) from Anguilla bicolor McClelland and Pisodonophis boro (Hamilton), respectively, from Thai brackish-water localities. Recently Purivirojkul (2009) treated larval ascaridoid nematodes of four genera (Anisa- kis Dujardin, 1845, Contracaecum Railliet et Henry, 1912, Porrocaecum Railliet et Henry, 1912 and Raphidascaris Railliet et Henry, 1915), not identified to species, from some fishes in the Gulf of Thailand and Yooyen et al. (2011a,b) described two species of Cucullanus Müller, 1777 and two of Procamallanus Baylis, 1923 from fishes in the Gulf of Thailand.

Parasitological examinations of some marine fishes in Hua-Hin, a coastal part of the Gulf of Thailand (Prachuapkhirikhan Province, Thailand), carried out from February to May 2009 yielded, among other helminths, adult ascaridoid nematodes belonging to the subgenus Ichthyascaris $\mathrm{Wu}, 1949$ of the genus Raphidascaris parasitizing two species of catfishes: spotted catfish Arius maculatus (Thunberg) and striped eel catfish Plotosus lineatus (Thunberg) (Ariidae and Plotosidae, respectively, both Siluriformes). Results of their taxonomic evaluation, based on detailed light microscopy (LM) and scanning electron microscopy (SEM) examinations, have indicated that they represent a new species, which is described herein.

Arius maculatus (maximum body length $80 \mathrm{~cm}$ ) and Plotosus lineatus (maximum body size $32 \mathrm{~cm}$ ) are tropical, commercial brackish-water and marine catfishes (the former also freshwater), widely spread in the Indo-Pacific; whereas the former species is distributed off the western and eastern coast of the Indian Subcontinent to the Arafura Sea and the Indo-Australian Archipelago (excluding Australia), the latter from the Red Sea and eastern Africa to Samoa, north to southern Japan, southern Korea and the Ogasawara Islans, south to Australia and Lord Howe Island; also in Palau and Yap in Micronesia (Froese \& Pauly, 2011).

\section{Materials and Methods}

All fish were bought from Khao-takiab fishery village $\left(12.57436^{\circ} \mathrm{N}, 99.95721^{\circ} \mathrm{E}\right)$, Hua-Hin District, Prachuap- 

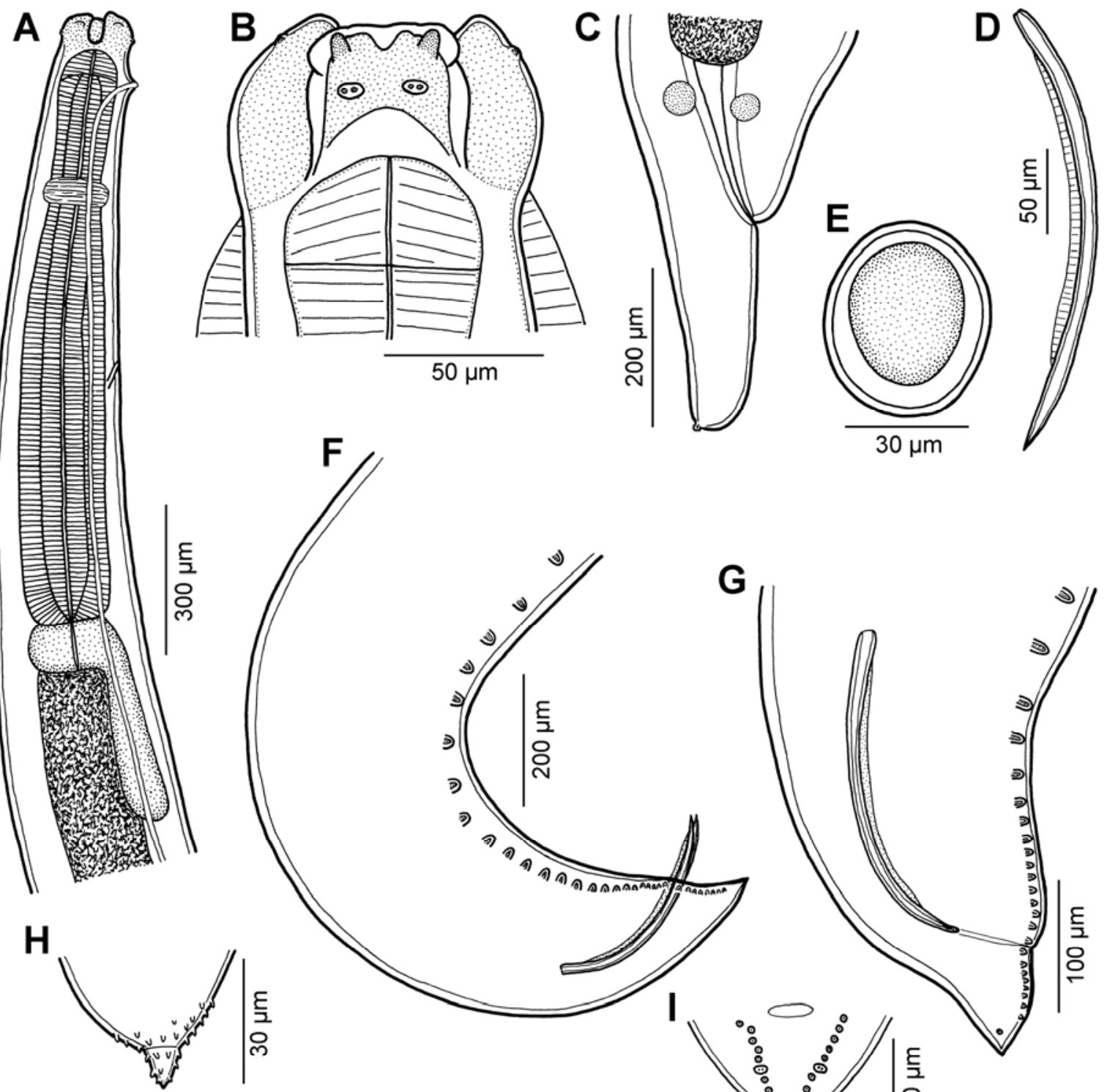

$\mathbf{F}$

H
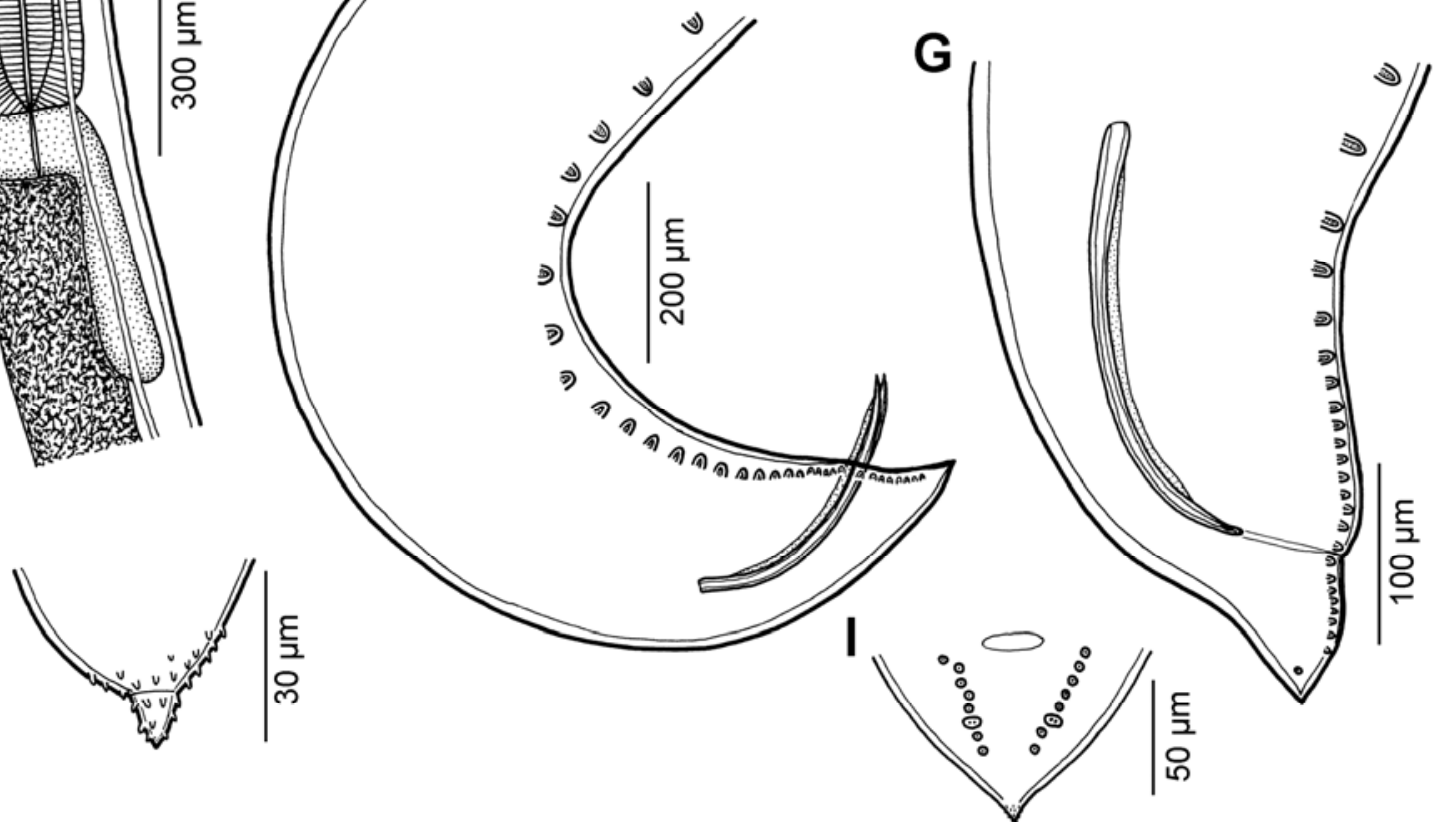

Fig. 1. Raphidascaris (Ichthyascaris) arii sp. n. from A. maculatus. A) Anterior end of male, lateral view; B) Cephalic end, dorsal view; C) Tail of gravid female, lateral view; D) Spicule, lateral view; E) Egg; F) Posterior end of male (with all pairs of caudal papillae), lateral view; G) Same (with incomplete number of preanal papillae), larger magnification; H) Tip of female tail, lateral view; I) Tail of male, ventral view.

khirikhan Province, Thailand in the period from February to May 2009. They were caught by a drift gill net. In total, 11 specimens of $A$. maculatus and 10 of $P$. lineatus were examined. The nematodes recovered were washed in physiological saline and then fixed in cold $4 \%$ formaldehyde solution. For light microscopy (LM) examination, the nematodes were cleared with glycerine. Drawings were made with the aid of a Zeiss drawing attachment. Specimens used for scanning electron microscopy (SEM) were postfixed in $1 \%$ osmium tetroxide (in phosphate buffer), dehydrated through a graded acetone series, critical-pointdried and sputter-coated with gold; they were examined using a JEOL JSM-7401F scanning electron microscope at an accelerating voltage of $4 \mathrm{kV}$ GB low. All measurements are in $\mu \mathrm{m}$ unless otherwise indicated. The names of fishes follow FishBase (Froese \& Pauly, 2011).

\section{Description}

Family Anisakidae Railliet et Henry, 1912

Raphidascaris (Ichthyascaris) arii sp. n. (Figs. 1-3)

\section{Description}

General: Medium-sized, whitish nematodes with transversely striated cuticle. Lips nearly equal in size (dorsal lip slightly smaller than ventrolateral lips), broader than long, without lateral membranous flanges; pulp with two distinct 
anterior lobes, each with terminal pocket-like depression (Fig. 2A - E). Dorsal lip bears two subdorsal double papillae at approximately anterior $1 / 3$ of its length; each ventrolateral lip with one double subventral papilla, one small single papilla and amphid situated laterally (Figs. 1B, 2E, F). Interlabia absent. Narrow lateral alae extend along almost whole body length, united anteriorly close to ventrolateral lips on one side of body (Figs 1A, 2B, C). Oesophagus short; posterior half markedly broad (Fig. 1A). Ventriculus transversely oval; ventricular appendix relatively short. Excretory pore well posterior to level of nerve ring. Tail of both sexes conical.
Male (6 specimens from $A$. maculatus; measurements of holotype in parentheses, those of 4 specimens from $P$. lineatus in brackets): Length of body $8.84-11.90$ (11.11) [5.71 - 12.01] mm, maximum width $245-544$ (354) [122 - 394]. Lips 54 - 68 (54) [27 - 54] long. Length of oesophagus $680-1,267$ (898) [830 - 966], representing 7 - 11 (8) [8 - 9] \% of body length, maximum width 95 204 (122) [109]. Nerve ring and excretory pore $272-394$ (286) [245 - 299] and 490 - 510 (510) [394 - 530], respectively, from anterior extremity. Ventriculus $60-120 \times$ $75-180(72 \times 93)[54-68 \times 82-122]$; ventricular appendix 246 - 381 (249) [299 - 340] long, 60 - 93 (72) [54]

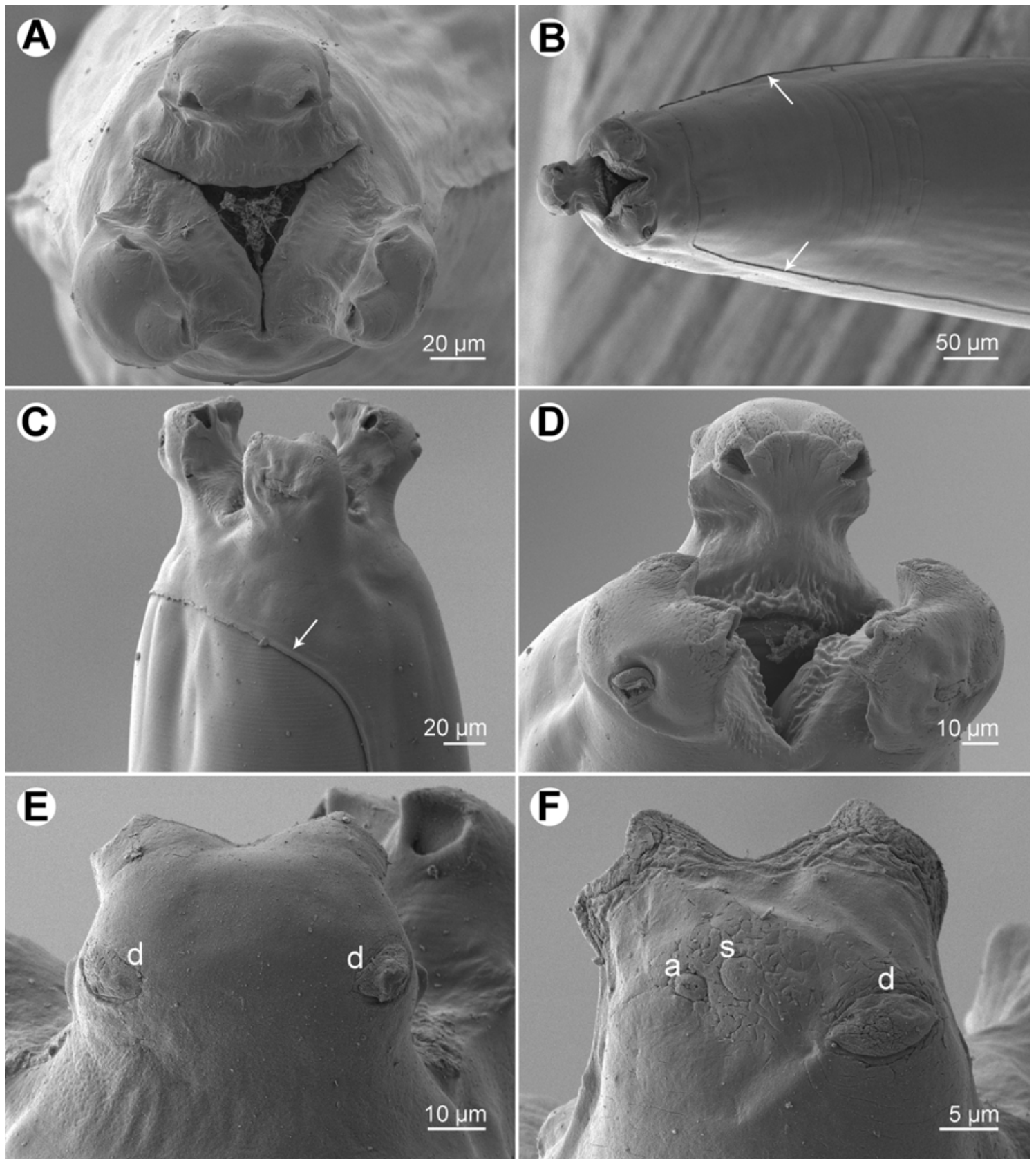

Fig. 2. Raphidascaris (Ichthyascaris) arii sp. n. from A. maculatus, scanning electron micrographs. A) Cephalic end, apical view; B) Anterior end of body; ventral view (arrows indicate lateral alae); C) Anterior end, sublateral view (arrow indicates ventral connection of lateral alae); D) Cephalic end showing inner structure of dorsal lip, ventral view; E) Dorsal lip; F) Subventral lip. a - amphid, d - double cephalic papilla, $\mathrm{s}$ - single cephalic papilla. 
in maximum width. Posterior end of body curved ventrally. Spicules equal, alate, pointed, 210 - 294 (270) [255 - 333] long, representing $2.4-2.6$ (2.4) [2.8 - 4.5] \% of body length (Figs. 1D, F, G). Total of $30-39$ (30) [33 - 38] pairs of small subventral papillae present, $21-27$ (21) [25 - 30] being preanals, 1 (1) [1] pair adanals and 8 (8) [8] postanals; papillae of several posteriormost preanal pairs and of adanal and postanal pairs very small; postanal papillae of third pair from posterior extremity doubled (Figs. $1 \mathrm{~F}, \mathrm{G}, \mathrm{I}, 3 \mathrm{C})$. Anterior cloacal lip with poorly developed unpaired median papilla. Tail 102 - 123 (123) [90 - 136] long, its tip bearing numerous small cuticular spikes and proturerances (Fig. 3D). terior region of body, $2.20-3.44(3.44)[2.92-3.67] \mathrm{mm}$ from anterior extremity, at $19-25$ (22) [22 - 29] \% of body length; vagina directed posteriorly from vulva. Uterus forms coils in region posterior to vagina, extending posteriorly to level of rectum. Eggs numerous, suboval to almost rounded, thin-walled, smooth, with uncleaved contents (Fig. 1E); size $45-51 \times 39-48(45-51 \times 42-48)$ [48 - $54 \times 39-42]$. Tail 394 (394) [126 - 286] long; tip with numerous minute cuticular spines (Fig. 1C, H).

Type host: Spotted catfish, Arius maculatus (Ariidae, Siluriformes).

Other host: Striped eel catfish, Plotosus lineatus (Plotosidae, Siluriformes).
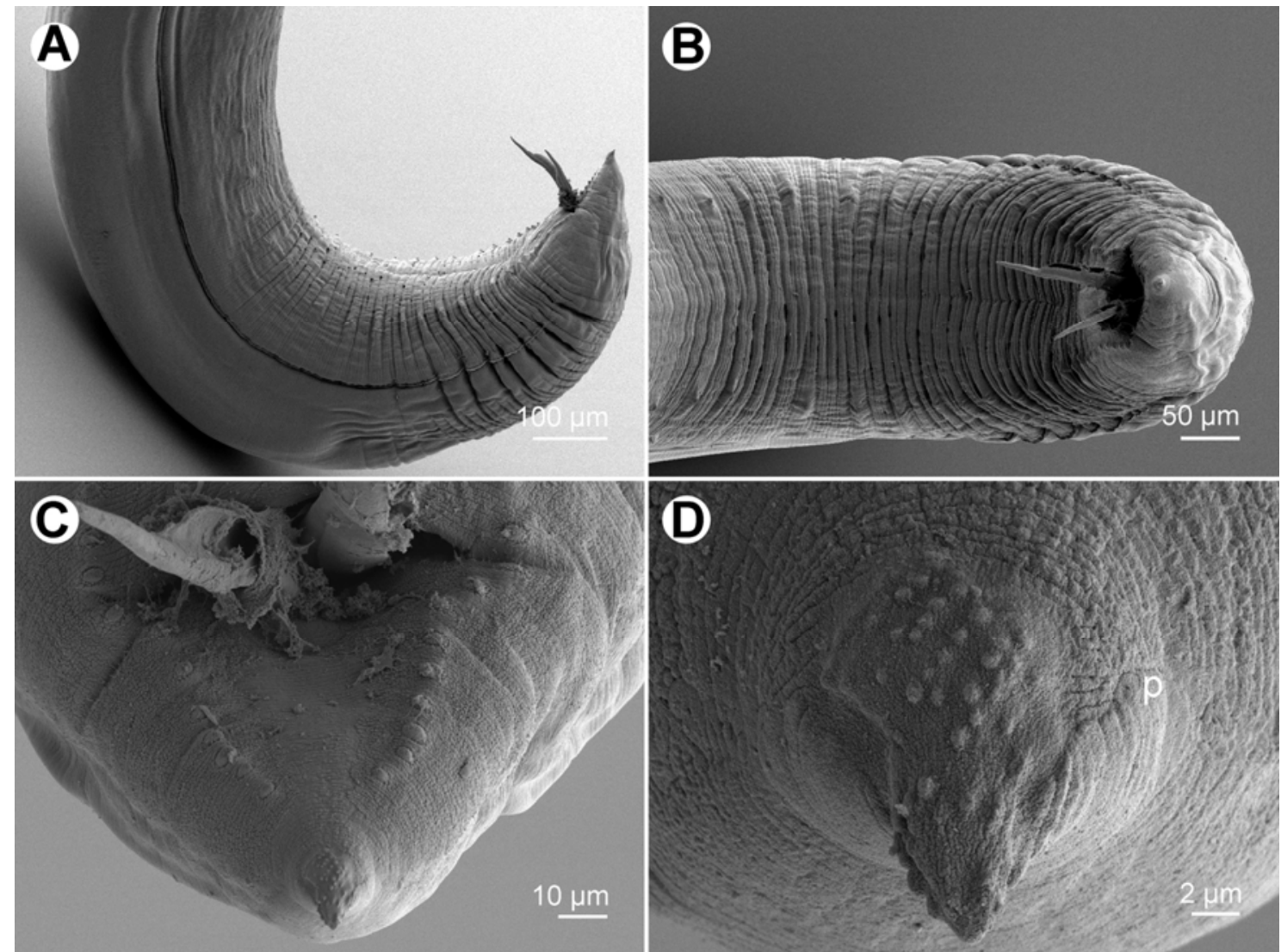

Fig. 1. Raphidascaris (Ichthyascaris) arii sp. n. from A. maculatus. A) Anterior end of male, lateral view; B) Cephalic end, dorsal view; C) Tail of gravid female, lateral view; D) Spicule, lateral view; E) Egg; F) Posterior end of male (with all pairs of caudal papillae), lateral view; G) Same (with incomplete number of preanal papillae), larger magnification; H) Tip of female tail, lateral view; I) Tail of male, ventral view.

Female (3 gravid specimens from A. maculatus; measurements of allotype in parentheses, those of 3 gravid specimens from $P$. lineatus in brackets): Length of body $11.56-$ 15.31 (15.31) [10.40 - 16.84] $\mathrm{mm}$, maximum width $367-$ 530 (530) [462 - 517]. Lips 68 (54) [54 - 68] long. Length of oesophagus $979-1,142(1,142)$ [898 - 1,278], representing $8-9$ (8) $[8-9] \%$ of body length, maximum width 136 - 190 (177) [109 - 204]. Nerve ring and excretory pore $272-449$ (449) [326 - 381] and $653-870$ (870) [639 $-680]$, respectively, from anterior extremity. Ventriculus $82 \times 122-136(82 \times 136)[82-95 \times 150-177]$; ventricular appendix 313 - 340 (340) [272 - 408] long, maximum width 54 - 68 (54) [41 - 95]. Vulva situated in an-
Site of infection: Intestine.

Type locality: Gulf of Thailand, Hua-Hin District, Prachuapkhirikhan Province, Thailand.

Prevalence and intensity: A. maculatus: $82 \%$ (9 fish infected/11 fish examined); 2 - 39 (mean 14). P. lineatus: $90 \%$ (9/10); $3-14(8)$.

Deposition of specimens: Holotype, allotype and paratypes (Cat. No. N-970) in the Helminthological Collection of the Institute of Parasitology, Biology Centre of the Academy of Sciences of the Czech Republic, in České Budějovice. Etymology: The specific name of this nematode relates to the genitive form of the generic name of the type host. 


\section{Discussion}

Wu (1949) established a new genus Ichthyascaris to accommodate his newly described species I. lophii Wu, 1949. However, subsequent authors (Hartwich, 1957; Chabaud, 1965; Smith, 1984; Moravec, 1994) considered Ichthyascaris a synonym of Raphidascaris Railliet et Henry, 1915. Bruce (1990) and Bruce et al. (1994) re-established Ichthyascaris as an independent genus mainly on the basis of simple lips without lateral membranous flanges and the presence of lateral alae, which unite close to the ventrolateral lips (see also Gibbons, 2010). However, Moravec \& Nagasawa (2002) redescribed the Japanese species Raphidascaris gigi Fujita, 1928, transferred to Ichthyascaris by Bruce (1990), and found that, while the lips were typical of Ichthyascaris, the lateral alae were lacking. The same concerns Raphidascaris lutjani Olsen, 1952 and $R$. mediterraneus Lèbre et Petter, 1983, both transferred by Bruce (1990) to Ichthyascaris (see Lèbre \& Petter, 1983; Smith, 1984). Therefore, Moravec and Nagasawa (2002) considered Ichthyascaris, characterized principally by the presence of lateral alae united anteriorly, as a subgenus of Raphidascaris. This conception has been followed by Moravec and Justine (2005, 2011).

At present, the following nine species can be considered to belong to the subgenus Raphidascaris (Ichthyascaris): $R$. chirocentri Yamaguti, 1935, R. etelidis Moravec et Justine, 2011, R. fisheri (Hooper, 1983), R. gymnocraniae (Bruce, 1990), R. lophii (Wu, 1949), R. nemipteri Moravec et Justine, 2005, R. sillagoides (Bruce, 1990), R. trichiuri (Yin et Zhang, 1983) and R. vicentei Santos, 1970.

The new species, $R$. arii sp. n., differs distinctly from $R$. fisheri and $R$. trichiuri in the presence of numerous small cuticular spines on the tail tip; from the former species also by the absence of a small bulge posterior to the anterolateral sockets on the lateral margins of the lips (see Bruce, 1990; Damin \& Heqing, 2001). From R. etelidis and $R$. lophii (the latter considered a species inquirenda by Smith, 1984) in a markedly shorter body of the gravid female ( $10-17$ vs. $24-27$ and $23-34 \mathrm{~mm}$, respectively) and spicules $(210-333$ vs. $345-474$ and $540-690$, respectively); from the former species also in less numerous pairs of preanal (21 - 30 vs. $44-49)$ and postanal (8 vs. 12 - 13) papillae (Wu, 1949; Moravec \& Justine, 2011). From $R$. vincentei it can be differentiated by the male tail tip with spines (vs. aspinose), less numerous pairs of postanal papillae ( 8 vs. $10-11)$ and of all caudal papillae $(30-39$ vs. $41-51)$, and by less elongate lips with protruding inner lobes (vs. more elongate lips without markedly protruding inner lobes) on their anterior ends (Smith, 1984).

In contrast to $R$. arii sp. n., the male tail tip of $R$. nemipteri is smooth (vs. spinose) (Moravec \& Justine, 2005), whereas the pairs of all caudal papillae and those of postanal papillae of $R$. chirocentri are more numerous (63 and 13 vs. $30-39$ and 8) (Yamaguti, 1935). The body length of $R$. sillagoides females is reported to be $9.5-30.2 \mathrm{~mm}$ (Bruce, 1990), but apparently also nongravid females were included; therefore, it can be deduced that gravid females of $R$. sillagoides are distinctly longer (up to 30.2 vs. $9.7-$ $16.8 \mathrm{~mm}$ ) than those of $R$. arii. In addition, $R$. sillagoides has a somewhat different shape of lips and its papillae of the third pair from the caudal extremity in the male are not doubled (Bruce, 1990).

By its morphology and measurements, $R$. arii seems to be closest to $R$. gymnocraniae, a species described from lethrinid fishes (Lethrinidae) of the South Pacific Ocean in the Australian region (Bruce, 1990). However, in contrast to $R$. arii, papillae of the third pair (counting from the caudal extremity) in R. gymnocraniae are single (Bruce, 1990). These two species also differ in the host orders (Perciformes vs. Siluriformes) and the geographical distribution. Bruce (1990) characterized the species of Ichtyascaris described by him (see also his generic diagnosis) as possessing lateral alae "forming cordons on tail". However, our observations show that, at least in $R$. etelidis, $R$. nemipteri and $R$. arii, this may concern only females, whereas lateral alae of males extend posteriorly only to a short distace anterior to the level of the cloacal aperture (i.e., they are missing on the tail).

All the hitherto described species of Raphidascaris (Ichtyascaris) differ from the new species in the type of hosts. Raphidascaris arii is the first nominal species of this subgenus reported from fishes of the order Siluriformes (see Bruce et al., 1994; Moravec \& Justine, 2005, 2011). All the above-mentioned species were described from other geographical regions (North and South Pacific near China, Japan, Australia and New Caledonia, and the Atlantic Ocean near Brazil) than $R$. arii. This is the first nominal species of this subgenus reported from the Gulf of Thailand. It is highly probable that the nematodes reported as Raphidascaris sp. by Purivirojkul (2009) from Plotosus anguillaris $(=P$. lineatus) from the Gulf of Thailand belonged to this newly described species.

\section{Acknowledgments}

We wish to express our thanks to the Office of the Higher Education Commission, Thailand, for supporting this research with a grant fund under the programme 'Strategic Scholarships for Frontier Research Network for the PhD Program Thai Doctoral Degree', and to the Applied Parasitology Research Laboratory, Department of Biology, Faculty of Science, Chiang Mai University, for providing necessary facilities. Thanks are also due to the staff of the Laboratory of Electron Microscopy, Institute of Parasitology, BC ASCR, in České Budějovice for their technical assistance, and to Blanka Škoríková of the same Institute for the help with illustrations. This study was partly supported by the research projects of the Institute of Parasitology, ASCR (Z60220518 and LC522).

\section{References}

Bhaibulaya, M. (1981): Ascaridoid nematode larvae in marine fishes from the Gulf of Thailand. Southeast Asian J. Trop. Med. Publ. Health, 12: 590 - 594 
BRUCE, N. L. (1990): Hysterothylacium Ward and Magath, 1917, and Ichthyascaris Wu, 1949, ascaridoid nematodes from Australian demersal fishes. Mem. Queensl. Mus., 28: $389-426$

Bruce, N. L., Adlard, R. D., Cannon, L. R. G. (1994): Synoptic checklist of ascaridoid parasites (Nematoda) from fish hosts. Invert. Taxon., 8: $583-674$

ChaBAud, A. G. (1965): Ordre des Ascaridida. In: Grassé, P.-P. (Ed.), Traité de Zoologie. Tome IV, fascicule 3. Masson et Cie, Paris, pp. 932 - 1025

DAMIN, L., HEQING, H. (2001): Heliconema minnanensis n. sp. (Physalopteroidea: Physalopteridae) and Raphidascaris trichiuri (Yin and Zhang) n. comb. (Ascaridoidea: Anisakidae) in marine fishes. J. Parasitol., 87: 1090 - 1094. DOI: 10.1645/0022-3395(2001)087[1090:HMNSPP]2.0.CO;2

DEARDORFF, T. L., OVERSTREET, R. M. (1981): Raphidascaris camura sp. n., Hysterothylacium uerycheilum (Olsen) comb. n., and comments on Heterotyphlum Spaul (Nematoda: Ascaridoidea). J. Parasitol., 67: 426 - 432

Froese, R., Pauly, D. (Eds) (2011): FishBase. World Wide Web electronic publication, version 05/2011. http://www.fishbase.org

GIBBONS, L. M. (2010): Keys to the nematode parasites of vertebrates. Supplementary volume. Wallingford, CABI, 416 pp.

HARTwiCH, G. (1957): Zur Systematik der Nematoden Superfamilie Ascaridoidea. Zool. Jahrb., Jena (Syst., Ökol. Geogr.), 85: $211-252$

LÈBre C., PetTer A. J. (1983): Deux nouvelles espèces d'Ascarides (Nematoda) parasites de Poissons Téléostéens: Raphidascaris mediterraneus n. sp. et Goezia anguillae n. sp.; complément de description de Cucullanus micropapillatus Törnquist, 1931 (Nematoda, Cucullanidae). Bull. Mus. Nat. Hist. Nat., $4^{\mathrm{e}}$ série, 5, section A, No. 2: 491 - 505

MoraveC, F. (1994): Parasitic nematodes of freshwater fishes of Europe. Prague and Dordrecht, Boston, London, Academia and Kluwer Academic Publishers, 473 pp.

Moravec, F., Justine, J.-L. (2005): Two anisakid nematodes from marine fishes off New Caledonia, including Raphidascaris (Ichthyascaris) nemipteri n. sp. from Nemipterus furcosus. Syst. Parasitol., 62: 101 - 110. DOI: 10.1007/s11230-005-5484-9

Moravec, F., Justine, J.-L. (2011): Raphidascaris (Ich- thyascaris) etelidis sp. n. (Nematoda: Anisakidae), a new ascaridoid nematode from lutjanid fishes off New Caledonia. Zoosystema, in press.

Moravec, F., NAGASAWA, K. (2002): Redescription of Raphidascaris gigi Fujita, 1928 (Nematoda: Anisakidae), a parasite of freshwater fishes in Japan. Syst. Parasitol., 52: $193-198$

Moravec, F., Taraschewski, H., AnAntaphruti, M. T., MAIPANICH, W., LAOPRASERT, T. (2006): Procamallanus (Spirocamallanus) anguillae sp. n. (Camallanidae) and some other nematodes from the Indonesian shortfin eel Anguilla bicolor in Thailand. Parasitol. Res., 100: $69-75$. DOI: $10.1007 / \mathrm{s} 00436-006-0245-5$

Moravec, F., TARASChEWSKi, H., AnANTAPHRUTI, M. T., MAIPANICH, W., LAOPRASERT, T. (2007): Heliconema longissimum (Ortlepp, 1923) (Nematoda: Physalopteridae) from Pisodonophis boro (Teleostei: Ophichthidae) in Thailand, with remarks on the taxonomy of the Proleptinae Schulz, 1927. Syst. Parasitol., 66: 73 - 80. DOI: 10.1007/s 11230-006-9066-2

PURIVIROJKUL, W. (2009): An investigation of larval ascaridoid nematodes in some marine fish from the Gulf of Thailand. Kasetsart J. (Nat. Sci.), 43: $85-92$

SIRIKANCHANA, P. (1982): Check lists of parasites of fishes in Thailand. Bangkok, Kasetsart University Museum of Fisheries, $11 \mathrm{pp}$.

SMith, J. D. (1984): Taxonomy of Raphidascaris spp. (Nematoda, Anisakidae) of fishes, with a redescription of R. acus (Bloch, 1772). Can. J. Zool., 62: 685 - 694. DOI: 10.1139/z84-100

WU, H. W. (1949): A note on two parasitic nematodes of fishes. Sinensia, 20: $51-57$

YAMAGUTI, S. (1935): Studies on the helminth fauna of Japan. Part 9. Nematodes of fishes, 1. Jpn. J. Zool., 6: 337 $-386$

Yooyen, T., Moravec, F., Wongsawad, C. (2011a): Two new species of Cucullanus Müller, 1777 (Nematoda: Cucullanidae) from marine fishes off Thailand. Syst. Parasitol., 78: 139 - 149. DOI: 10.1007/s11230-010-9286-3

Yooyen, T., Moravec, F., Wongsawad, C. (2011b): Two new sibling species of Procamallanus (Spirocamallanus) (Nematoda: Camallanidae) from marine fishes in the Gulf of Thailand. J. Parasitol., 97: 931-938. DOI: 10.1645/GE-2806.1 